\title{
Poesin däremellan - estetiska lärprocesser i praktik och teori
}

Torben Freytag

Det är den tolfte februari 2016 och jag skall hålla en avslutande intervju med tre flickor som går i en klass i årskurs 7. Under hösten året innan har jag genomfört en fem veckor lång interventionsstudie i deras klass. Under intervjun kommer vi in på begreppet estetiska lärprocesser då följande samtal kom att utspelas:

Jag: - Ja, estetiska lärprocesser kallas det här... tycker ni att det är ett bra namn för det här arbetet?

Elev $\mathrm{I}:-\mathrm{Mm}$

Elev 2 och 3:- Jaa (unisont)!

Jag: - Eller har ni ett bättre förslag på vad det skulle kunna heta? Elev I: - Eget tänkande... kanske (fniss)?

Jag: - Ja, men det har ju handlat... du har ju àterkommit till det. $\ddot{A} r$ det någonting du tänker... kanske?

Elev I: - Estetisk...? Ja... men det är väl bra som det heter?

Elev 3: - Jag tycker också det är bra!

Utdraget ovan är hämtat från den licentiatuppsats som jag just nu håller på att skriva klart och är tänkt att brygga över till ämnet för detta kapitel, nämligen estetiska lärprocesser. Precis som intervjuutdraget ovan illustrerar vill jag i detta kapitel beskriva hur detta estetiska lärprocesser kan förstås utifrån olika perspektiv. Inledningsvis gör jag en översiktlig beskrivning av fältet estetiska lärprocesser. Därefter kommer jag in på hur jag själv utifrån olika positioneringar förhåller mig till begreppet. I de två påföljande avsnitten diskuteras hur estetiska lärprocesser kan förstås utifrån

Hur du refererar till det här kapitlet:

Freytag, T. 20I 8. Poesin däremellan - estetiska lärprocesser i praktik och teori. I: von Schantz, U., Thorgersen, K. and Lidén, A. (red.) De estetiska ämnenas didaktik Utmaningar, processer och protester. Pp. I83-I94. Stockholm: Stockholm University Press. DOI: https://doi.org/Io.I6993/ bap.m. License: CC-BY 
en skolkontext och hur man inom vissa teorier ser på begreppet. Avslutningsvis vill jag göra en kortare beskrivning hur jag har genomfört min undersökning.

\section{Estetiska lärprocesser - från olika håll}

Estetiska lärprocesser har idag utvecklats till ett eget akademiskt fält och ämnesområde inom framför allt lärarutbildningen. ${ }^{\mathrm{I}}$ I stort definieras fältet av frågor som hur estetiska uttrycksformer och estetisk kommunikation kan användas i undervisningen och hur det estetiska finns närvarande i skolans ämnen. ${ }^{2}$ I Stockholm, vid Stockholms universitet och Södertörns högskola, finns numera kurser med just denna inriktning inom fältet för estetiska lärprocesser. Fältet informations- och kommunikationsteknik (IKT), som är en annan inriktning, intresserar sig för estetiska lärprocesser med betoning på multimodalt berättande. ${ }^{3}$ Detta fält representeras av Institutionen för data- och systemvetenskap (DSV). ${ }^{4}$ På Stockholms universitet, Kungliga Tekniska högskolan och KTH Kista bedrivs numera en verksamhet för Informations- och kommunikationsteknik (ICT-skolan). ${ }^{5}$ Tydligt är att intresset för estetiska lärprocesser kan ses från många olika håll.

Jag, som licentiand på en forskarskola och lärare i bild och svenska på en grundskola, möter estetiska lärprocesser på olika sätt. I mina forskningsstudier handlar mötet med estetiska lärprocesser om utforskandet och formulerandet om vad estetiska lärprocesser är och kan vara. Däremot, i min roll som bild- och svenskalärare på högstadiet, så handlar mötet snarare om görandet och iscensättandet av estetiska lärprocesser. Utöver dessa två positioneringar så bildar jag också som en slags länk mellan teori och praktik i min roll som koordinator i nätverket för praktiskestetiska ämnen på STLS (Stockholm Teaching \& Learning Studies). ${ }^{6}$ I denna roll så stöttar och handleder jag ämnesdidaktiska utvecklingsprojekt inom de praktisk-estetiska ämnena som lärare på skolor i Stockholms stad, Nacka och Botkyrka kommun har ansökt till. Lärarna som jag möter i denna roll är ofta väl förtrogna med det praktiska görandet inom sitt ämne och det som de vill undersöka, men behöver oftast stöttning i det metodologiska och det teoretiska. Denna uppdelning av hur jag på olika 
sätt förhåller mig till detta begrepp kan kanske ses som väl kategorisk, men ger ändå en bild av hur jag i min olika roller förhåller mig till detta begrepp. Vad denna inledning har velat visa är att beroende på positionering så kan mötet med estetiska lärprocesser se väldigt olika ut.

\section{Estetiska lärprocesser i skolpraktiken}

Är då estetiska lärprocesser något självklart i skolans värld? Ja, i alla fall om man läser läroplanen. Även om begreppet estetiska lärprocesser inte ordagrant används i läroplanen så framhålls exempelvis värdet av estetiska aspekter under de inledande målen under skolans värdegrund och uppdrag:

Skolan ska stimulera varje elev att bilda sig och växa med sina uppgifter. I skolarbetet ska de intellektuella såväl som de praktiska, sinnliga och estetiska aspekterna uppmärksammas.7

Formuleringar som sådana, menar jag, bildar stöd för att arbeta med estetiska lärprocesser i skolan. En viktig skillnad i en jämförelse av nuvarande läroplan med förutvarande är att i Lgri I så används inte estetiska lärprocesser en enda gång, däremot används formuleringar som 'estetiska upplevelser', 'estetiska val' eller 'estetiska uttrycksformer'. Så istället för att tala om det estetiska som en lärprocess så används andra ord. Möjligen innebär detta en annan syn på det estetiska. Enligt Hansson Stenhammar (20I5) så är estetikens roll i dagens läroplan att utveckla ett kritiskt tänkande. ${ }^{8}$

I min egen forskning har jag utgått ifrån hur estetiska uttrycksformer skrivs fram i ämnet svenska. Utifrån en frågeställning som handlar om hur elever upplever att uttrycka sig estetiska har jag velat ta reda hur elever på högstadiet tycker om detta. 'Estetiska uttrycksformer' är också något som ingår i Svenska-ämnets syfte, men är också ett kunskapskrav i årkurs 6 och 9. Under syftet för ämnet svenska är 'estetiska uttrycksformer' något som eleverna skall stimuleras till att uttrycka sig med.

Eleverna ska även stimuleras till att uttrycka sig genom olika estetiska uttrycksformer. ${ }^{9}$ 
Noterbart är att eleverna skall stimuleras till att kombinera "olika estetiska uttrycksformer" vilket skapar ett utrymme för flera estetiska uttrycksformer. I kunskapskraven för svenska (och svenska som andra språk) i årkurs 6 och 9, i kunskapskraven för betygen $\mathrm{E}$ till A formuleras hur olika estetiska uttryck kan förstärka och levandegöra elevers texters budskap i olika grad.

Genom att kombinera text med olika estetiska uttryck så att de samspelar på ett $i$ huvudsak fungerandeländamålsenligt/ändamålsenligt och effektivt sätt kan eleven förstärka och levandegöra sina texters budskap. ${ }^{\text {1० }}$

Det estetiskas roll kan här ses som ett verktyg för att förstärka och levangöra. En ofta refererad studie i forskning om estetiska lärprocesser är Lindgrens avhandling från 2006. Det Lindgren kommer fram till är fem diskurser för hur lärare ser på estetisk verksamhet. Gemensamma drag för dessa fem diskurser är estetisk verksamhet som något förstärkande och kompensatoriskt för undervisningen. ${ }^{\text {I }}$

\section{Estetiska lärprocesser i teorin}

Begreppet estetiska lärprocesser är, och som Thorgersens inledande kapitel i denna antologi illustrerar, ett problematiskt och svävande begrepp. Inom skolan och forskning svävar så väl lärare, pedagoger som forskare på svaret om vad begreppet egentligen betyder och om detta namn gör begreppet rättvisa. ${ }^{\mathrm{I} 2}$ Sanningen är väl att det finns flera både möjliga, önskvärda och potentiella innebörder av begreppet och ett ord eller en enda mening är med andra ord inte tillräckligt. ${ }^{\mathrm{I} 3}$ Enligt min mening redogörs begreppet bättre utifrån hur det används i sammanhang. Björck anser att en estetisk lärprocess är när någon form av skapande används för att ge uttryck för en upplevelse eller förståelse av något. ${ }^{14}$ Häggström (20II) för fram att en estetisk lärprocess kan beskrivas, precis som andra lärprocesser, som ett unikt lärande som har sina egna utmärkande kännetecken. ${ }^{15}$ Hansson Stenhammar (2015) hävdar att estetiska lärprocesser innebär ett skapande som tar sin utgångspunkt i konstnärliga metoder som kan beskrivas i termer 
som kreativitet, reflektion, experimenterande, undersökande, gränsöverskridande och fantiserande. ${ }^{16}$ Det vi kan sluta oss till utifrån dessa beskrivningar är att estetiska lärprocesser innehåller kreativt skapande där just skapandeprocessen är i fokus.

Själva lärandet i en estetisk lärprocess brukar beskrivas som en nomadisk och transdisciplinär process som möjliggör ett vad man kallar, rhizomatiskt tänkande. ${ }^{17}$ Begreppet rhizom används metaforiskt för att beskriva läroprocessen. ${ }^{18}$ Den rhizomatiska metaforen används för att beskriva hur går till lärandet i en estetisk lärprocess. ${ }^{19}$ Likt rhizomer går lärandet här i oförutsägbara banor som inte på något sätt följer några bestämda linjer. I detta tänkande samverkar olika disciplinära och "språkliga" fenomen på olika sätt, och ofta över och mellan olika ämnesdiscipliner. ${ }^{20}$

Lindström (2008) hävdar att estetiska lärandestrategier kan beskrivas i fyra dimensioner. Enligt Lindström kan lärandet ske om, $i$, med och genom estetiska lärprocesser. Inom dessa dimensioner används ett lärande som antingen kan vara entydigt eller mångtydigt. Lärandet är antingen mediespecifikt eller medieneutralt, det vill säga vissa göranden är förknippade med vissa ämnen, medan andra göranden är mindre bundna. ${ }^{21}$ Enligt forskare som Bamford (2006) finns det en betydande skillnad mellan undervisning i estetiska ämnen och undervisning genom estetiska ämnen. ${ }^{22}$ Estetiska lärprocesser kan också ses som verktyg för

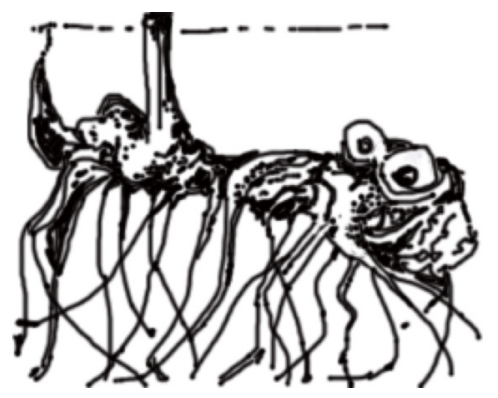

Bild 1. Rhizom (författarens egen illustration): - Hej, mitt namn är Rhizom! Jag går $i$ oförutsedda banor. Copyright: Författaren delas här med en CC BY-licens. 
identitetsskapande. Drotner (I99I) anser att estetiskt gestaltande kan hjälpa elever i deras identitetsskapande, det vill säga att få kännedom om sig själva. ${ }^{23}$

\section{Iscensättning av en estetisk lärprocess}

Till att börja med, att iscensätta en estetisk lärprocess är inget som låter sig göras i en handvändning. Kring detta vittnar många röster, och inte minst jag själv kan stämma in i denna kör. Häggström (20I2) hävdar att när man skall iscensätta estetiska lärprocesser i skolan, så handlar det inte om att läraren skall anpassa sig till undervisningen, utan snarare att undervisningen skall anpassas efter eleverna. ${ }^{24}$ Hansson- Stenhammar (2016) kommer fram till att lärprocesser formas utifrån lärarens didaktiska val, inte av ämnet.

Min undersökning handlar om högstadieelevers uppfattningar av undervisning med estetiska uttrycksformer när de arbetar med skönlitterära texter. I läroplanens formuleringar om skolans uppdrag (Skolverket, 20I I, s. 9) framställs det estetiska ämnesområdet i två skepnader, dels som en del av lärandet, och dels som inslag i skolans verksamhet. Läroplanens otydliga beskrivning av vad det estetiska ämnesområdet skall innebära och tillföra medför också svårigheter för skolor att förhålla sig till detta. I nuvarande läroplan för grundskolan har skolämnena fått ett större ämnesdjup och den ämnesintegrerade undervisningen har minskat. Dock förekommer även antydningar i läroplanen i de två inledande kapitlen som pekar mot ämnesintegrerade arbetssätt:

... läraren skall organisera och genomföra arbetet så att eleven får möjligheter till ämnesfördjupning, överblick och sammanhang, och fär möjlighet att arbeta ämnesövergripande. ${ }^{25}$

I tre relativt nyutkomna rapporter från Skolverket, rapporter 423 , 424,425 , har man intervjuat lärare i praktisk-estetiska ämnen som bild, musik och slöjd. I dessa framkommer det att många praktisk-estetiska lärare upplever att man samarbetar mindre över ämnesgränser sedan Lgrıı:s införande. Rapport 425 om 
slöjdämnet visar att övergripande samarbeten i grundskolan minskar högre upp i stadierna. ${ }^{26}$

Utifrån scenariot, att elever sällan eller aldrig arbetar ämnesintegrerat med estetiska uttryck, har jag iscensatt en så kallad intervention där estetiska uttryck prövas i samband med läsning av olika sorters skönlitterära texter. En övergripande frågeställning i min studie har handlat om hur högstadieelever upplever att arbeta med estetiska uttrycksformer i samband med läsning av skönlitterära texter. En underliggande frågeställning har handlat om elevernas upplevelser av en sådan undervisning. För knyta an till Lindström så handlar min studie om ett lärande genom estetiska lärprocesser. ${ }^{27}$ För att besvara studiens frågor genomförde jag därför en intervention $i$ en högstadieklass. Insamlingen av data genomfördes under hösten $20 \mathrm{I} 5$ på en kommunal skola i en

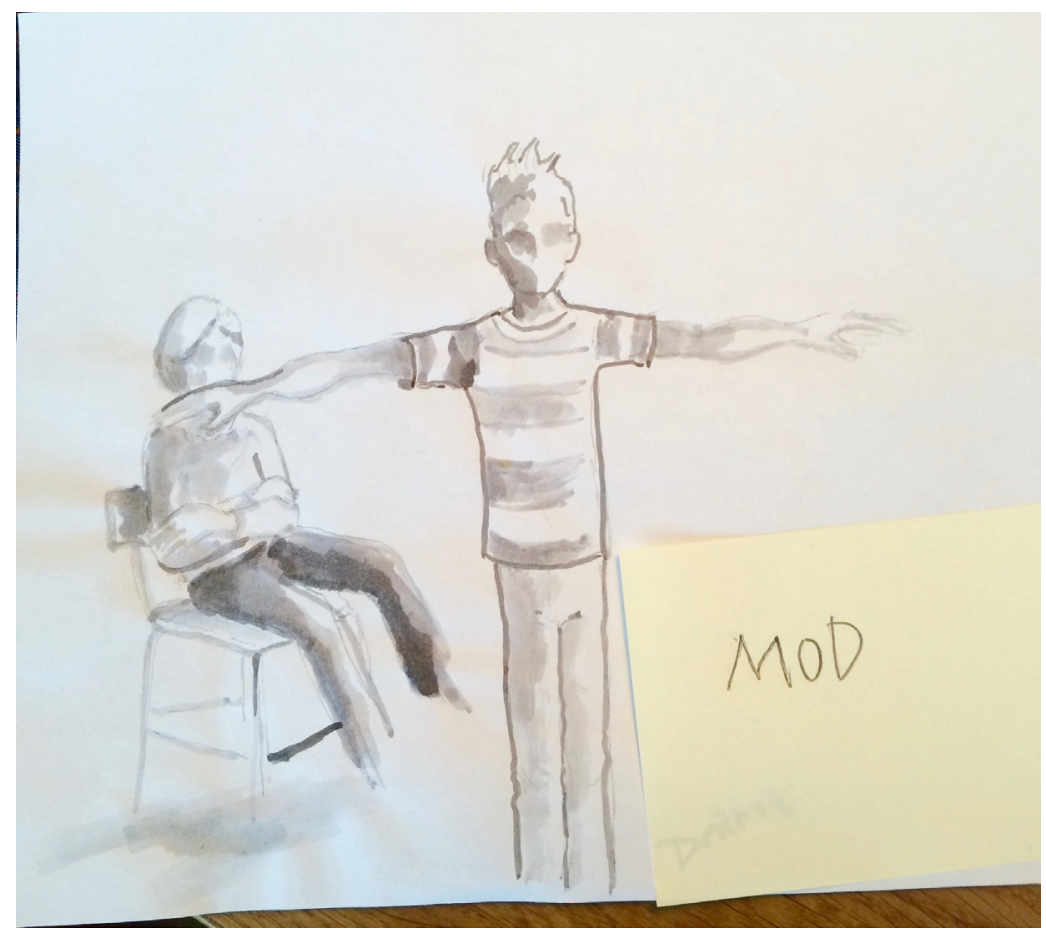

Bild 2. Drama (exempel på författarens egen skiss under insamlingen). Copyright: Författaren. 
klass i årkurs 7 med 30 elever. ${ }^{28}$ Lektionsdesignen utformades tillsammans med de medverkande lärarna på skolan. Uppgiften som eleverna skulle utföra var att omsätta tolkningar av skönlitterära texter i estetiska uttryck som drama, film och musik. Eleverna arbetade med uppgiften på bild-, musik- och svenska-lektioner under ledning av klassens ordinarie lärare i respektive ämnen. Under interventionen följde jag klassen, både som oberoende och deltagande observatör beroende på situation. ${ }^{29}$ Under interventionen dokumenterade jag elevernas arbetsprocess med hjälp av film- och ljudupptagningar, men också med egna skisser.

Filmerna och ljudupptagningarna kom sedan att bilda utgångspunkter i intervjuerna med eleverna. Skisserna har jag i huvudsak använt som ett dokumenterande bildmaterial, men också som ett Stimulated Recall-material i intervjuerna. Det huvudsakliga datamaterialet har bestått av de intervjuer som jag har genomfört, både före, under och efter interventionen. För att synligöra vidden av uppfattningar kring estetiska uttrycksformer har jag använt mig av en fenomenografisk analysmetod $\mathrm{i}$ analysen av intervjuerna. I analysprocessen har jag iterativt läst materialet fram och tillbaka för att hitta representativa teman. Utifrån dessa teman har jag kommit fram till sex beskrivningskategorier.

Studiens teoretiska ramverk består av sociokulturell teori i bemärkelsen att allt lärande är situerat, John Deweys teorier om hur mänsklig erfarenhet tar form och hur estetik och att skapande får mening i erfarandet och görandet. ${ }^{3 \circ} \mathrm{Jag}$ har även anlagt ett multimodalt perspektiv på lärande eftersom studien fokuserar på elevernas syn på estetiska lärprocesser i görandet. Det multimodala perspektivet knyter an till Deweys teorier om meningsskapande och skapande i ett sammanhang, men också i synen på erfarenhet (Ibid). Den fenomenografiska analysen visar att uttrycka sig estetiskt kan beskrivas i kategorier som 'Att uttrycka sig fritt', 'Att tolka och gestalta', 'Att pröva olika perspektiv' och 'Att få andra att förstå'. Elevernas upplevelser av undervisning med estetiska uttrycksformer kan beskrivas i kategorier som 'Att visa kunskap på andra sätt', 'Att samarbeta', 'Mediespecifikt lärande' och 'Att inte lära sig sà värst mycket'. Var för sig och tillsammans kan dessa kategorier ses som uppslag för att försöka säga något mer om hur 
elever upplever att uttrycka sig estetiskt och hur de upplever en sådan undervisning.

Just den konstnärliga upplevelsen är något som kan användas i undervisningen, menar jag. Det ger flera av eleverna uttryck för i intervjuerna i denna studie, inte minst i kategorier som 'Att uttrycka sig fritt', 'Att tolka och gestalta', 'Att pröva olika perspektiv' och 'Att få andra att förstå'. Enligt Dewey finns det en språklig dimension i olika estetiska uttryckssätt och som jag också har kunnat spåra i min studie. Deweys beskrivning av språk kan ses som en vidgad förståelse av text, men också som ett multimodalt perspektiv på lärande.

Objects of art are expressive. They are language. Rather they are many languages. For each art has its own medium and that medium is especially fitted for one kind of communication.

\section{Slutnoter}

I. Burman, A. 20I4:7. Konst och lärande, essäer om estetiska lärprocesser.

2. Lindstrand, F. \& Selander, S. (red.). 2010. Estetiska lärprocesser upplevelser, praktiker och kunskapsformer.

3. IKT (eller dess engelska motsvarighet, ICT) är en förkortning för Informations- och kommunikationsteknik är det begrepp som används inom skolan. I många andra branscher används istället begreppet IT. Då skolorna i Sverige just nu genomgår en digitaliseringsprocess finns ett stort behov av fortbildning inom IKT.

4. Kandidatprogram i marknadskommunikation och IT, I $80 \mathrm{hp}$. http://dsv.su.se/utbildning/alla-utbildningar/kandidatprogram/ markit (Hämtad 20I 8-06-08).

5.Utbildning inom elektroteknik och datavetenskap. https:/www.kth.se/ ict/utbildning/utbildning-pa-grundniva-ı.7905 (hämtad 2018-06-08).

6. Stockholm Teaching \& Learning Studies (STLS) har utvecklats för att initiera, stödja och sprida lärarledda forskningsprojekt som handlar om frågor och problem som uppstår i klassrummet. Den övergripande tanken är att STLS ska fungera som en mötesplats för forskande lärare i olika ämnen. Plattformen är ett samarbete mellan skolhuvudmän och kommuner i Stockholms län och Stockholms universitet. 
7. Skolverket, 20I I:Io. Läroplan för grundskolan, förskoleklassen och fritidshemmet.

8. Hansson Stenhammar, 20 I 5 . En avestetiserad skol- och lärandekultur. En studie om lärprocessers estetiska dimensioner.

9. Skolverket, 20 I I: I, Svenska, och svenska som andra språk.

IO. Skolverket 20I I:9-I I, kunskapskrav i svenska och svenska som andra språk; Skolverket 20I I:I2-I4, Kunskapskrav i åk 9 i svenska och svenska som andra språk.

I I. Lindgren, 2006:92-Iог. Att skapa ordning för det estetiska. I skolan-diskursiva positioneringar i samtal med lärare och skolledare.

I 2. Lindström, 2008:57-6I. Estetiska lärprocesser om, i, med och genom slöjd.

I3. Ibid.

I4. Björck, 20I4. Klicka där: En studie om bildundervisning med datorer.

I 5. Häggström, 20I I:66. Att iscensätta lärande i estetiska ämnen. Ett exempel frä bildområdet.

I6. Hansson Stenhammar, 20 1 5:4-6.

I7. Kress, I997. Before writing. Rethinkng the paths to literacy.

I 8. Rhizom ett filosofiskt begrepp som har utvecklats av Giles Deleuze och Félix Guattari. Begreppet är hämtat ifrån växtriket där rhizom är ett slags rotsystem. Till skillnad från vanliga rötter så växer rhizomer åt olika håll. Delueze och Guattari använder begreppet rhizom för att beskriva organiseringsmönster hos människor, idéer och böcker.

I9. Selander \& Kress. 20I0:I7. Design för lärande - ett multimodalt perspektiv.

20. Ibid.

2I. Lindström, 2008.

22. Bamford, 2006. The Wow Factor: Global Research Compendium on the Impact of the Arts in Education.

23. Drotner, I991. At skabe sig-selv: ungdom, cestetik, pedagogik.; Häggström, M. 20 I I:67. Att iscensätta lärande i estetiska ämnen. Ett exempel från bildområdet. 
24. Skolverket 20I I: kap I och 2, sid I I.

25. Skolverket, 201 5:17. Slöjd i grundskolan. En nationell ämnesutvärdering $i$ årskurs 6 och 9.

26. Lindström, 2008.

27. Det inledande intervjuutdraget är hämtat ifrån den datainsamling som jag gjorde i samband med interventionen, hösten 2015.

28. Bryman, A. 20 I I. Sambällsvetenskapliga metoder 2.

29. Dewey, I958. Art as experience.

\section{Referenser}

Bamford, A. 2006. The Wow Factor: Global Research Compendium on the Impact of the Arts in Education. Waxmann Verlag GMBH, Germany.

Björck, C. 20I4. Klicka där: En studie om bildundervisning med datorer. Institutionen för etnologi, religionshistoria och genus- vetenskap, Centrum för de humanistiska ämnenas didaktik, Stockholms universitet.

Bryman, A. 20I I. Sambällsvetenskapliga metoder. 2., [rev.] uppl. Malmö: Liber.

Burman, A. 20I4. Konst och lärande, essäer om estetiska lärprocesser. Huddinge: Södertörns Högskola..

Dewey, J. 1958. Art as experience. New York: Capricorn.

Drotner, K. I99I. At skabe sig-selv: ungdom, æstetik, padagogik, I. udg., I. opl., Gyldendal, København.

Hansson Stenhammar, M-L. 2015. En avestetiserad skol- och lärandekultur. En studie om lärprocessers estetiska dimensioner. GU. Göteborg.

Kandidatprogram i marknadskommunikation och IT, ı 80 hp. http:// dsv.su.se/utbildning/alla-utbildningar/kandidatprogram/markit (Hämtad 20I 8-06-08).

Häggström, M. 20I . Att iscensätta lärande $i$ estetiska ämnen. Ett exempel från bildområdet. Inst. För didaktik och pedagogisk profession. Göteborgs universitet.. 
Kress, G.I997. Before writing. Rethinkng the paths to literacy. London: Routledge.

Lindgren, M. 2006. Att skapa ordning för det estetiska. I skolan - diskursiva positioneringar $i$ samtal med lärare och skolledare. Göteborgs universitet:.

Lindstrand, F. \& Selander, S. (red.). 2oro. Estetiska lärprocesser upplevelser, praktiker och kunskapsformer. Lund: Studentlitteratur.

Lindström, L.2008. Estetiska lärprocesser om, i, med och genom slöjd. Kritisk Utbildningstidskrift. $\mathrm{Nr}_{3} 33 / \mathrm{I} 34$ ( ( $\left.-2 / 2008\right)$.

Skolverket, 20II. Läroplan för grundskolan, förskoleklassen och fritidshemmet. Skolverket, Stockholm.

Selander \& Kress. 20Iо. Design för lärande - ett multimodalt perspektiv. Norstedts.

Skolverket 2o I Ia. Kunskapskrav i åk 9 i svenska och svenska som andra språk. Kursplan.

Skolverket, 20 I rb. Svenska, och svenska som andra språk. Kursplan.

Skolverket, 20I 5 . Slöjd i grundskolan. En nationell ämnesutvärdering i årskurs 6 och 9. Rapport 425.

Utbildning inom elektroteknik och datavetenskap. https:/www.kth.se/ ict/utbildning/utbildning-pa-grundniva-I.7905 (hämtad 20I 8-06-08). 